\title{
Non-Allergic Rhinitis with Osteopathic Treatment Techniques
}

\author{
Omar Bukhari, DO PGY2'; Grant Phillips, MD'; Kathleen Sweeney, DO \\ IUPMC Altoona - Altoona Family Physicians, Altoona, PA
}

\author{
KEYWORDS: \\ Non-Allergic Rhinitis \\ Osteopathic Manipulative \\ Medicine
}

ABSTRACT: Rhinitis is generally classified as allergic or non-allergic and is differentiated from conditions that mimic symptoms of rhinitis. This article reviews the non-allergic forms of rhinitis highlighting signs, symptoms and diagnosis. An in-depth overview of osteopathic treatment options for the head and neck are outlined to assist osteopathic family physicians in providing symptom relief to their non-allergic rhinitis patients.

\section{INTRODUCTION}

Non-allergic rhinitis (NAR) is a heterogeneous condition rather than a specific disease. It is characterized by periodic or perennial symptoms of rhinitis that are not a result of IgE-dependent events or infectious in origin. These include non-allergic rhinopathy, infectious rhinitis, and rhinitis caused by foods or alcohol. ${ }^{1}$ NAR disproportionately affects women; who tend to suffer from recurring headaches and recurrent sinusitis as well. ${ }^{2}$ NAR affects about $7 \%$ of the U.S. population. ${ }^{3}$

The extensive mucosal area of the nose provides a surface for warming and humidification of inspired air and removal of air pollutants. Physical and chemical stimuli can elicit specific nasal sensations, including olfaction, warming or cooling, irritation and nasal pruritus. These stimuli can trigger nasal secretion or and obstruction.

NAR is defined by symptoms where there is some combination of sneezing, rhinorrhea, nasal congestion, and postnasal drainage in the absence of a specific etiology. Non-allergic rhinopathy replaced the term vasomotor rhinitis (VMR) since the term VMR implies the involvement of nasal vascular and glandular abnormalities contributing to inflammation and current data suggest that NAR is due to neurosensory abnormalities with minimal inflammation. NAR is a heterogeneous disorder that includes anatomic abnormalities, endogenous atopy, nociceptive nerve dysfunction and autonomic dysfunction ${ }^{4}$ and is probably due to neurosensory abnormalities not inflammation. ${ }^{5}$ NAR should be differentiated from other causes of rhinitis that include infectious and allergic subtypes, among other causes.

\section{CORRESPONDENCE:}

Omar Bukhari, DO PGY2 | bukharimo2@upmc.edu

Copyright $\odot 2020$ by the American College of Osteopathic Family Physicians. All rights reserved. Print ISSN: 1877-573X

$10.33181 / 12023$

\section{DIFFERENTIAL DIAGNOSIS}

Infectious rhinitis is an acute process generally secondary to viral infections or secondary bacterial infection. Symptoms include nasal congestion, mucopurulent nasal discharge, pain and pressure, headache, olfactory disturbance, postnasal drainage, and cough. Viral infections account for as many as $98 \%$ of acute infectious rhinitis and the majority of rhinitis symptoms in children. ${ }^{6}$ Conditions associated with NAR include acute and chronic sinusitis, headaches, asthma, chronic cough, conjunctivitis, otitis media with or without effusion, nasal polyps, hearing impairment, obstructive sleep apnea, and other sleep disturbances.

Allergic rhinitis is an IgE-mediated inflammatory process of the nasal mucosa prompted by environmental allergens that are often seasonal. ${ }^{7}$ These patients tend to have more sneezing and itchy eyes compared to patients with NAR, and asthma is more common. ${ }^{2}$

\section{SIGNS AND SYMPTOMS AND DIAGNOSIS}

The diagnosis of NAR is made on clinical grounds and starts with a careful history and physical. Some authors suggest skin testing or in vitro testing for seasonal and perennial aeroallergens to rule out an allergic component. ${ }^{8}$ Start by identifying the pattern, seasonality, related symptoms response to medications and an environmental history. Primary symptoms of NAR are nasal congestion and rhinorrhea. Secondary symptoms might include throat clearing, cough, ear pressure or popping, sneezing, reduced ability to smell and to detect odors (hyposmia) and facial pressure or headache. Symptoms may be continuous or intermittent and may be influenced by one or more precipitating factors. ${ }^{9}$

Physical examination for NAR is more variable than in allergic rhinitis and therefore is of limited value in differentiating rhinitis subtypes. The nasal mucosa is normal or erythematous, often with evidence of prominent postnasal drip with cobblestoning or may appear red and beefy with scant mucus. ${ }^{10}$ Note that if the 
patient is asymptomatic, the physical exam may be normal. Shortand long-term complications decreased quality of life and include chronic cough, poor cognitive functioning, daytime fatigue, reduced productivity, and absenteeism.

\section{TREATMENT}

Treatment is symptomatic. First-line treatment should include avoidance of triggers when practicable. There is evidence that topical saline is beneficial in the treatment of the symptoms when used alone or as an adjunctive treatment. ${ }^{6}$ Other treatments include intranasal steroids, intranasal antihistamines, a combination of both and oral decongestants. Oral second-generation antihistamines are minimally effective. Though first-generation oral antihistamines may haves some benefit due to anticholinergic activity, use of these medications may impair cognitive function and in worst-case scenarios lead to an increase in motor vehicle crashes. ${ }^{11}$

Intranasal ipratropium bromide is helpful when rhinorrhea is the predominant symptom. It is more effective when used in combination with an intranasal cortico $\neg$ steroid than either drug alone. The main side effect is dryness of the nasal mucosa. ${ }^{6}$

\section{OSTEOPATHIC TECHNIQUES FOR THE HEAD AND NECK}

Restrictions in cranial movement can lead to altered subtle mobility of the parietal and temporal bones interfering with the proper articulation of the cranial bones and the primary respiratory mechanism. Restriction in the sphenoid and occiput relationship can lead to different movements of the frontal, parietal, temporal bones, which can influence patients' ear, nose and throat complaints.

If the physician is familiar with basic cranial osteopathic manipulative technique (OMT) the CV4 compression technique and frontal sinus lift can be utilized to normalize cranial motion. Most Osteopathic physicians that practice in-depth cranial OMT take courses beyond what is the standard curriculum in medical school that are not in

\section{TABLE 1:}

Treatment summary

\begin{tabular}{|l|l|l|}
\hline TREATMENT & LEVEL OF EVIDENCE & REFERENCES \\
\hline $\begin{array}{l}\text { Avoidance of } \\
\text { known triggers }\end{array}$ & Level C & 6 \\
\hline Nasal saline & Level A & 6 \\
\hline Oral antihistamines & Level C & 12 \\
\hline $\begin{array}{l}\text { Intranasal } \\
\text { corticosteroids }\end{array}$ & Level A & 12,13 \\
\hline $\begin{array}{l}\text { Intranasal } \\
\text { antihistamines }\end{array}$ & Level A & 6 \\
\hline $\begin{array}{l}\text { Intranasal } \\
\text { anticholinergics }\end{array}$ & Level A & 6 \\
\hline Oral decongestants & Level A & 6 \\
\hline
\end{tabular}

the scope of this review. The approach described below includes easily mastered OMT techniques that provide symptom relief and often can be taught in the office to the patient or family member to utilize at home.

The clinician's approach could include releasing the thoracic inlet, hyoid, cricoid and thyroid cartilage release, cervical chain drainage techniques, submandibular release, mandibular drainage/ Galbreath technique, auricular drainage technique, alternating nasal pressure, trigeminal nerve decongestion and effleurage of the maxilla and frontal sinuses. Correction of cervical somatic dysfunction and treatment of parasympathetic and sympathetic influences can also be addressed. This suggested order allows for optimal lymphatic flow, but a busy family physician most commonly will adapt and utilize the techniques they feel are most efficacious and that can be performed in the constraints of the standard office visit.

\section{Release of Thoracic Inlet}

The physician decompresses the thoracic inlet by correcting the asymmetry of the soft tissues and fascia. This is done by screening the thoracic inlet in all three planes of motion which are bounded by the first rib, first thoracic vertebra, and the clavicles. The physician palpates the soft tissues and boney landmarks to ascertain the freedom and restrictions. The physician then applies an indirect or direct force to normalize motion and symmetry. This lymphatic technique allows for freer movement of lymphatic drainage from the head and regions that are subsequently treated. Treatment of restrictions of the first rib may also be considered.

\section{FIGURE 1:}

Release of the thoracic inlet

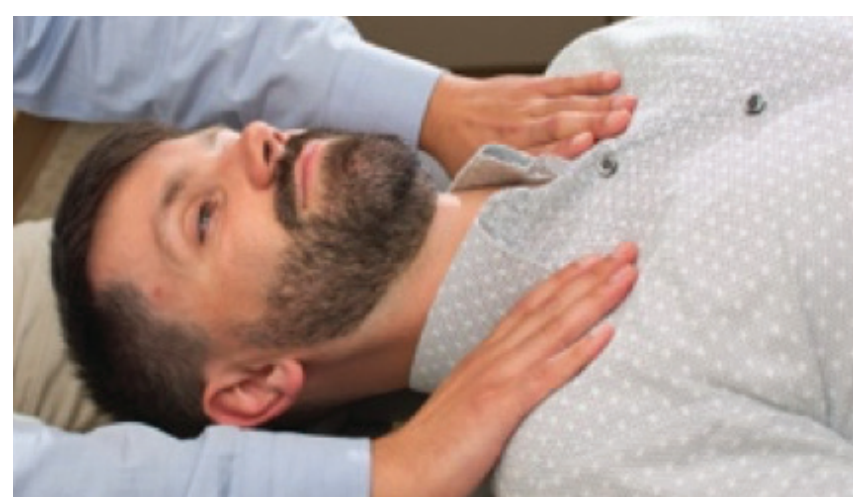

Hyoid, Cricoid and Thyroid Cartilage Release

The physician gently articulates the cartilage of the hyoid bone, cricoid cartilage and thyroid cartilage while stabilizing the head gently with the opposite hand at the forehead or occiput.

\section{Cervical Chain Drainage}

The physician downwardly displaces the sternocleidomastoid muscle and uses a "milking" motion along the span of the muscle from a caudad to cephalad direction to facilitate cervical lymphatic drainage. 


\section{Submandibular Release}

The physician uses the tips of the fingers to assess the ease of motion and symmetry of the submandibular fascia.

\section{FIGURE 2:}

\section{Submandibular release}

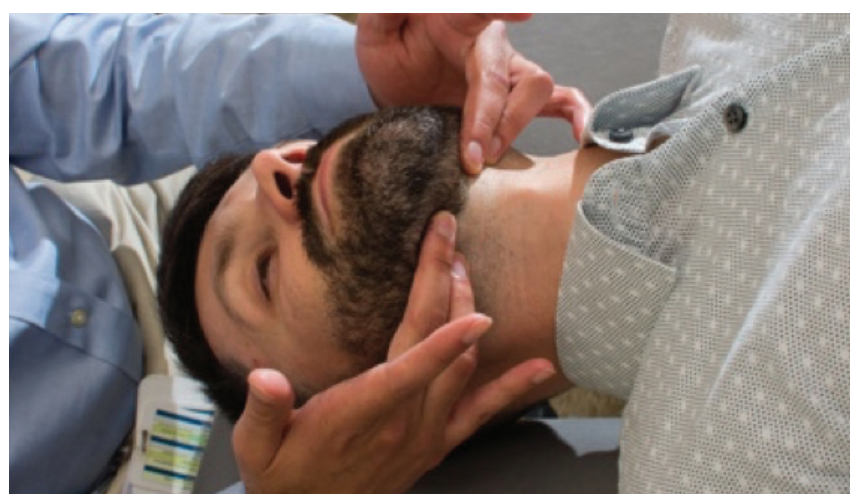

\section{Mandibular Drainage/Galbreath maneuver}

The physician places one hand to stabilize the head and then uses the fingers and hypothenar eminence to gently ease the mandible forward and toward the midline in a slow and rhythmic motion.

This technique can help relieve the dysfunction of the eustachian tubes and is helpful for lymphatic congestion in the ear, nose, throat and submandibular region. Care must be taken in patients with temporomandibular pain and dysfunction to not stress the joint or cartilage.

\section{FIGURE 3:}

Mandibular drainage/Galbreath maneuver

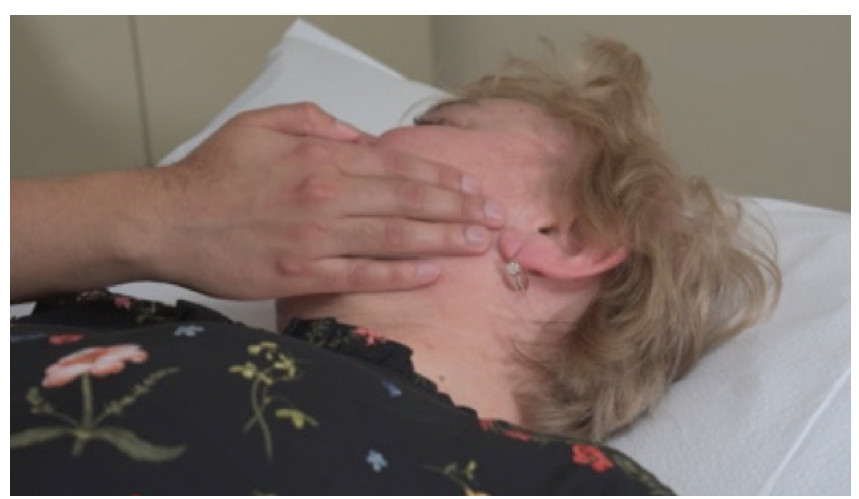

Auricular Drainage

The outer ear is stabilized and secured between the third and fourth digits of the physician's dominant hand while the other hand stabilizes the head. The hand applied to the external ear then makes gentle circles in clockwise direction ending with a gentle tug on the tragus. This technique can be taught to patients and family members.
FIGURE 4:

Teaching patient auricular drainage

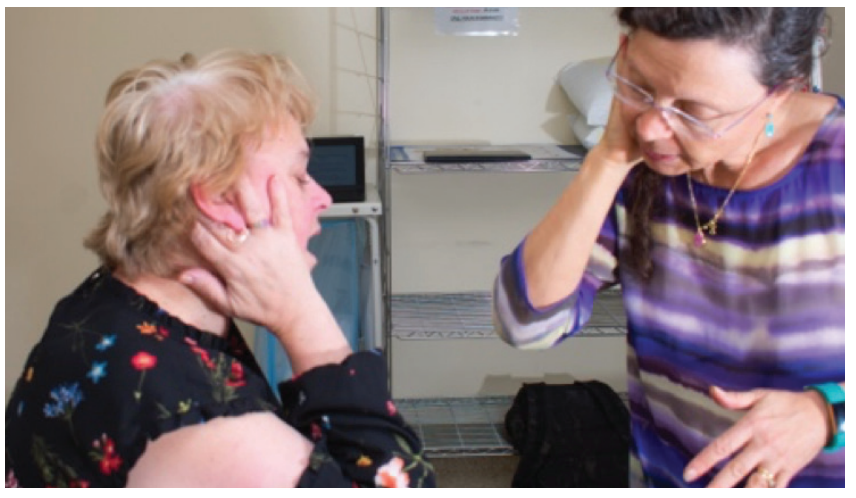

\section{Alternation Nasal Pressure}

The physician or patient presses in a diagonal fashion downward on the ethmoid sinus in a rhythmic pattern to facilitate lymphatic drainage through the sinus.

Trigeminal Nerve Decompression at the supra, infra and mental foramina

The physician or patient uses the pads of the fingers to apply gently rotary pressure to decompress the trigeminal nerve at the areas of exit of the branches of cranial nerve $\mathrm{V}$ in the V1, V2 and V3 distribution. These foramina are easily palpated and can be shown to the patient or family member for home treatment.

\section{FIGURE 5:}

Trigeminal nerve decompression



\section{Maxillary and Frontal Effleurage}

The physician gently strokes the patient's skin over the maxillary and frontal sinuses. To treat the maxilla, the motion is medial to lateral, beginning at the infraorbital foramina and moving toward the zygoma. In the frontal area the treatment begins medial to the eyebrow and moves laterally.

\section{FIGURE 6:}

Teaching patient auricular drainage



\section{FIGURE 7:}

Maxillary technique

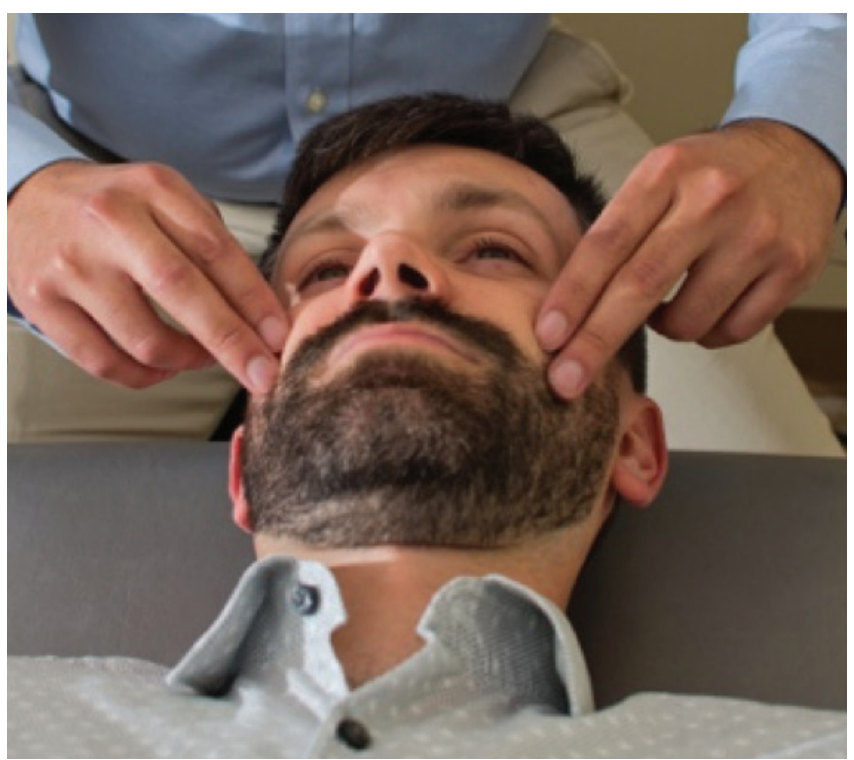

\section{Cervical Somatic Dysfunction}

Correcting cervical dysfunctions can aid with lymphatic drainage from the head to the major lymphatic channels. Treatment of cervical dysfunction can also decrease muscle tone in the cervical spine leading to less headaches and congestion.

\section{Sympathetic and Parasympathetic Influences}

Treatment in the upper thoracic region T1 -T5 normalizes the sympathetic output to the head and neck region. Treating the Sphenopalatine ganglion with short intermittent pressure inside the mouth with a gloved finger can enhance parasympathetic activity and encourage thin watery secretions facilitating sinus and nasal drainage. Sub-occipital release is also useful at the occipitoalatlantal articulation influencing the vagus nerve. Those experienced in other in-depth cranial techniques can apply these to affect the parasympathetic influence in the head region.

\section{RECOMMENDED RESOURCES}

Three excellent textbooks for the novice or experienced family physician to review Osteopathic manual medicine techniques are the 5 Minute OMM Consult by Millicent Channell, DO and David C. Mason DO, Atlas of Osteopathic Techniques by Alexander S. Nicholas, DO and Evan A. Nicholas, DO and Somatic Dysfunction in Osteopathic Family Medicine by Kenneth Nelson, DO. 14,15,16 The techniques described in this article can be furthered explored in these resources. The latter two resources have accompanying video content.

\section{CONCLUSION}

NAR is a common complaint that includes symptoms including some erythema of the nares, sinus drainage, sinus pressure, and sinus headaches. It is treated with nasal saline irrigation, nasal antihistamines, nasal anticholinergics, nasal steroids, antihistamines, and avoidance of triggers. Allergy testing is recommended to rule out allergic causes in some cases. Osteopathic treatment can be used to treat not only symptoms that may be seen with this condition but also to eliminate the predisposing dysfunctions of the head and neck which can contribute to worsening symptoms in patients.

\section{ACKNOWLEDGMENTS}

Special appreciation to Dr. Michael Geishauser, Pharm.D. and Karen Isenberg for use of their images in the writing of this article.

\section{AUTHOR DISCLOSURES:}

No relevant financial affiliations or conflicts of interest.

\section{REFERENCES:}

1. Wallace DV, Dykewicz MS, Bernstein DI, Blessing-Moore J, Cox L, Khan DA, Lang DM, Nicklas RA, Oppenheimer J, Portnoy JM, Randolph CC, Schuller D, Spector SL, Tilles SA; Joint Task Force on Practice; American Academy of Allergy; Asthma \& Immunology; American College of Allergy; Asthma and Immunology; Joint Council of Allergy, Asthma and Immunology.The diagnosis and management of rhinitis: an updated practice parameter.J Allergy Clin Immunol. 2008 Aug;122(2 Suppl):S1-84. doi: 10.1016/j.jaci.2008.06.003.

2. Mølgaard E(1), Thomsen SF, Lund T, Pedersen L, Nolte H, Backer V. Differences between allergic and non-allergic rhinitis in a large sample of adolescents and adults. Allergy. 2007 Sep;62(9):1033-7. Epub 2007 Jun 18. 
3. Settipane RA(1), Kaliner MA. Chapter 14: Non-allergic rhinitis. Am J Rhinol Allergy. 2013 May-Jun;27 Suppl 1:S48-51. doi: 10.2500/ ajra.2013.27.3927.

4. Baraniuk JN. Pathogenic mechanisms of idiopathic non-allergic rhinitis. World Allergy Organ J. 2009 Jun 15;2(6):106-14. doi: 10.1097/ WOX.0b013e3181aadb16.

5. Kaliner MA(1), Baraniuk JN, Benninger MS, Bernstein JA, Lieberman P, Meltzer EO, Naclerio RM, Settipane RA, Farrar JR. Consensus Description of Inclusion and Exclusion Criteria for Clinical Studies of Non-allergic Rhinopathy (NAR), Previously Referred to as Vasomotor Rhinitis (VMR), Non-allergic Rhinitis, and/or Idiopathic Rhinitis. World Allergy Organ J. 2009 Aug 15;2(8):180-4. doi: 10.1097/WOX.0b013e3181b2ff8a.

6. Wallace DV, Dykewicz MS, Bernstein DI, Blessing-Moore J, Cox L, Khan DA, Lang DM, Nicklas RA, Oppenheimer J, Portnoy JM, Randolph CC, Schuller D, Spector SL, Tilles SA; Joint Task Force on Practice; American Academy of Allergy; Asthma \& Immunology; American College of Allergy; Asthma and Immunology; Joint Council of Allergy, Asthma and Immunology.The diagnosis and management of rhinitis: an updated practice parameter. J Allergy Clin Immunol. 2008 Aug;122(2 Suppl):S1-84. doi: 10.1016/j.jaci.2008.06.003.

7. Emeryk A(1)(2), Emeryk-Maksymiuk J(3), Janeczek K(2). New guidelines for the treatment of seasonal allergic rhinitis. Postepy Dermatol Alergol. 2019 Jun;36(3):255-260. doi: 10.5114/ada.2018.75749. Epub 2019 Jun 18.

8. Settipane RA(1), Kaliner MA. Chapter 14: Non-allergic rhinitis. Am J Rhinol Allergy. 2013 May-Jun;27 Suppl 1:S48-51. doi: 10.2500/ ajra.2013.27.3927.

9. Kaliner MA(1), Baraniuk JN, Benninger MS, Bernstein JA, Lieberman P, Meltzer EO, Naclerio RM, Settipane RA, Farrar JR. Consensus Description of Inclusion and Exclusion Criteria for Clinical Studies of Non-allergic
Rhinopathy (NAR), Previously Referred to as Vasomotor Rhinitis (VMR), Non-allergic Rhinitis, and/or Idiopathic Rhinitis. World Allergy Organ J. 2009 Aug 15;2(8):180-4. doi: 10.1097/WOX.0b013e3181b2ff8a.

10. Greiwe J(1), Bernstein JA(2). Non-allergic Rhinitis: Diagnosis. Immunol Allergy Clin North Am. 2016 May;36(2):289-303. doi: 10.1016/j. iac.2015.12.006. Epub 2016 Mar 12.

11. Orriols $L(1)$, Luxcey $A(2)$, Contrand $B(2)$, Bénard-Laribière $A(3)$, Pariente $A(4)$, Gadegbeku B(5), Lagarde E(2). Road traffic crash risk associated with prescription of hydroxyzine and other sedating $\mathrm{H} 1$-antihistamines: A responsibility and case-crossover study. Accid Anal Prev. 20 NAD Sep;106:115-121. doi: 10.1016/j.aap.2017.05.030. Epub 2017 Jun 8.

12. Angier E(1), Willington J, Scadding G, Holmes S, Walker S; British Society for Allergy \& Clinical Immunology (BSACI) Standards of Care Committee. Management of allergic and non-allergic rhinitis: a primary care summary of the BSACI guideline. APrim Care Respir J. 2010 Sep;19(3):217-22. doi: 10.4104/pcrj.2010.00044.

13. Lieberman PL, Smith P. Non-allergic rhinitis: treatment. Immunol Allergy Clin North Am. 2016; 36(2): 305-319.

14. Nicholas, Alexander S., and Evan A. Nicholas. Atlas of Osteopathic Techniques. Wolters Kluwer, 2016. Immunol Allergy Clin N Am 36 (2016) 289-303.ttp://dx.doi.org/10.1016/j.iac.2015.12.006

15. Nelson, Kenneth, Somatic Dysfunction in Osteopathic Family Medicine Philadelphia, PA: Wolters Kluwer Health/Lippincott Williams \& Wilkins, 2007, This textbook was developed by the ACOFP Committee on Osteopathic Principles and Practice

16. Channell, Millicent King., and David C. Mason. The 5-minute Osteopathic Manipulative Medicine Consult. Philadelphia, PA: Wolters Kluwer Health/ Lippincott Williams \& Wilkins, 2009. Print.

\section{Forging Our Osteopathic Future: Donor Honor Roll}

ACOFP Foundation leaders would like to recognize the following individuals for their tremendous contributions to the Forging Our Osteopathic Future fundraising initiative.

Thank you all for your support.

Pinnacle Donors $(\$ 50,000+)$

Jeffrey S. Grove, DO, FACOFP dist.

Diamond Donors (\$25,000+)

Eugene M. DiBetta, Jr., DO

Carol L. Henwood, DO, FACOFP dist.

Paul A. Martin, DO, FACOFP dist.

Emerald Donors (\$15,000+)

Larry W. Anderson, DO, FACOFP dist.

Nicole H. Bixler, DO, MBA, FACOFP

Greg D. Cohen, DO, FACOFP dist.

Robert C. DeLuca, DO, FACOFP dist.

Kenneth Heiles, DO, FACOFP dist.

Brian A. Kessler, DO, FACOFP dist.

Dewey McAfee, DO, FACOFP

Saroj Misra, DO, FACOFP

Kevin V. de Regnier, DO, FACOFP dist.

Thomas N. Told, DO, FACOFP dist.

Nicholas Tyszka, JD and Alicia A. Martin, DO

Bruce R. Williams, DO, FACOFP

\section{Ruby Donors (\$10,000+)}

Katherine Galluzzi, DO, FACOFP dist.

David J. Park, DO, FACOFP
Sapphire Donors $(\$ 5,000+)$

Clinton Adams, DO

Guatam J. Desai, DO, FACOFP

Gary Edwards, DO, FACOFP dist.

Joel M. Feder, DO, FACOFP dist.

James E. Froelich, III. DO, FACOFP dist.

Ronnie B. Martin, DO, FACOFP dist.

Rance McClain, DO, FACOFP

Joseph P. Molnar, DO, FACOFP dist.

Bob Moore, CAE

Jennifer M. Olson, DO

Elizabeth Palmarozzi, DO, FACOFP

Sonia Rivera-Martinez, DO, FACOFP

William M. Silverman, DO, FACOFP dist.

Antonios J. Tsompanidis, DO, FACOFP

Rodney M. Wiseman, DO, FACOFP dist.

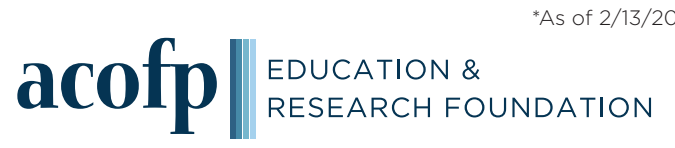

For more information, please contact us at foundation@acofp.org or (254) 624-3219. 